\title{
Factors Associated With Body Image Perception Among Brazilian Students From Low Human Development Index Areas
}

The Journal of School Nursing $1-9$

(C) The Author(s) 2017 Reprints and permission: sagepub.com/journalsPermissions.nav DOI: $10.1177 / 1059840517718249$ journals.sagepub.com/home/jsn @SAGE

\author{
Thábyta Silva de Araujo, PhD Student', Valter Cordeiro Barbosa Filho, PhD², \\ Fabiane do Amaral Gubert, PhD', Paulo César de Almeida, PhD³, \\ Mariana Cavalcante Martins, PhD', \\ Queliane Gomes da Silva Carvalho, PhD Student', \\ Ana Cristina Pereira de Jesus Costa, $\mathrm{PhD}^{4}$, and \\ Neiva Francenely Cunha Vieira, PhD'
}

\begin{abstract}
This study aimed to evaluate sociodemographic, behavioral, and individual factors associated with body image perception in a sample of adolescents from schools in low Human Development Index areas in Brazil. This cross-sectional study included 609 boys and 573 girls (aged II-I7 years). Body image perception (nine-silhouettes scale) and sociodemographic, behavioral, and individual variables were included. Multinomial logistic regression analysis was used. Most boys (76.9\%) and girls (77.5\%) were dissatisfied with their body image. Body mass index status and healthy body image evaluation were significantly associated with body image dissatisfaction in both boys and girls $(p<.001)$, and daily fruit consumption was associated with body image dissatisfaction only in boys $(p=.035)$. Education and health care focused on body image can pay special attention to young people from vulnerable areas with unhealthy nutritional status and focus on strategies that enable improving the perception of a healthy body and a healthy diet.
\end{abstract}

\section{Keywords}

body image, youth, socioeconomic factors, mental health, lifestyle

Body image is a multidimensional and dynamic concept in which the perceptions of body images and ideas are formed based on experiences, concepts, and behaviors. The relationship between the body and cognitive processes such as beliefs, values, and individual and/or social attitudes comprises body image perception, that is, an individual's perception of real and desirable body attributes (Paludo et al., 2011; Petroski, Pelegrini, \& Glaner, 2012).

The evaluation of body image perception is important because it can represent the individual's susceptibility to social, cultural, and epidemiological changes in a society, and how these changes can impact self-perception (Laus et al., 2014; Petroski et al., 2012). In particular, adolescents tend to be more susceptible and influenced by social and physiological changes. The acceptance of these changes and how adolescents deal with them in front of friends, family, and community are essential to body image perception (Fidelix, Silva, Pelegrini, Silva, \& Petroski, 2011). When body image dissatisfaction occurs among adolescents, other psychological and health problems may appear, such as depression, suicidal ideation, and eating disorders (Langoni, Aerts, Alves, \& Câmara, 2012; Lee \& Lee, 2016). Therefore, studies should focus on epidemiological monitoring of body image perception among adolescents as well as identify variables that are associated with the presence of body image dissatisfaction in youth (Carvalho, Paiva, \& Aparício, 2013;

\footnotetext{
' Federal University of Ceará, Fortaleza, Brazil

${ }^{2}$ Federal University of Santa Catarina, Florianópolis, Brazil

${ }^{3}$ State University of Ceará, Fortaleza, Brazil

${ }^{4}$ Federal University of Maranhão, Imperatriz, Brazil
}

\section{Corresponding Author:}

Thábyta Silva de Araujo, PhD Student, Federal University of Ceará, III5 Alexandre Barauna Street, Fortaleza, Ceará, BR 60430-160, Brazil.

Email: thabyta.araujo@hotmail.com 
The Journal of School Nursing $X X(X)$

Farhat, Iannotti, \& Caccavale, 2014; Lundberg et al., 2011; Reina et al., 2013).

Some variables have been studied as potential factors associated with body image perception among adolescents. Firstly, body image perception and its correlates tend to be designed and constructed differently between genders (Ribeiro \& Oliveira, 2011). Sociodemographic characteristics, such as low socioeconomic status and opportunities for health education, as well as limited resources and access to health services; behavioral factors such as physical activity, eating habits, sexual behaviors, alcohol, and tobacco use; and individual aspects, for example, nutritional status and self-rated health, have been associated with difficulties in dealing with perception of body image among adolescents (Cortês, Meireles, Friche, Caiaffa, \& Xavier, 2013; Hernando, Nunes, Torres, Lemos, \& Valadas, 2013; Lamis, Malone, Langhinrichsen-Rohling, \& Ellis, 2010; Langoni et al., 2012; Lundberg et al., 2011; Reina et al., 2013).

Most previous studies were conducted in developed countries (Farhat et al., 2014; Hernando et al., 2013; Lamis et al., 2010; Reina et al., 2013), while studies involving adolescents from socially vulnerable areas are scarce. Areas with high social vulnerability are common in low-and middle-income countries; this vulnerability is usually considered when the Human Development Index (HDI) is up to 0.699 (United Nations Development Programme [UNDP], 2016).

The HDI is a composite index ranging from 0 to 1 based on three dimensions of human development: a long and healthy life, access to knowledge, and a decent standard of living. It is the geometric mean of normalized indices for each of the three dimensions (UNDP, 2016).

Inhabitants in these areas tend to live in poor and highrisk conditions and have difficulty in accessing education and good nutrition (Malik, 2014). Thus, it is important to understand socioeconomic, behavioral, and individual variables that can have a negative impact on health indicators, for example, body image perception, in adolescents from these vulnerable areas.

A study exploring body image perception among adolescents can provide information to aid in developing strategies to promote health and body image satisfaction among adolescents from vulnerable areas and alleviate risk conditions for mental health issues. Thus, the present study aimed to evaluate sociodemographic, behavioral, and individual factors associated with body image perception in a sample of adolescents from schools in low HDI areas in Brazil.

\section{Method}

\section{Study Design and Participants}

This is a cross-sectional study using the baseline data from the "Fortaleça sua Saúde"/"Strengthen Your Health" project, a cluster-randomized controlled trial carried out in public schools in Fortaleza, northeastern Brazil (Clinicaltrials.gov: NCT02439827). The National Research Ethics System approved the study protocol (protocol No. 17366313.9.0000.0121). Fortaleza is the capital of the state of Ceará, northeastern Brazil, and has a population of $2,452,185$ inhabitants, which makes it the fifth largest city in Brazil in terms of population. This municipality has an area of $314 \mathrm{~km}^{2}$ and an HDI of 0.754 (19th HDI among the 27 Brazilian state capitals (Instituto Brasileiro de Geografia e Estatistica [IBGE], 2010).

This study included a randomized sample of 1,182 students (609 boys and 573 girls), aged 11-17 years. They represent $92.9 \%$ of the total students enrolled in Grades 79 from all six full-time public schools, representing one school in each administrative region of the municipality in Fortaleza, northeastern Brazil, during the 2014 school year. The neighborhood HDI where the six schools were located was $0.170,0.215,0.341,0.377,0.443$, and 0.491 (IBGE, 2010). The closer the HDI score to 1 , the better the level of human development; and the closer to 0 , the worse the level of development (UNDP, 2016).

Consent for students' participation was obtained from a parent/guardian by signing an informed consent form, according to the ethical considerations advocated in Brazil. A detailed description of the sample selection and methods can be found in a previous publication (Barbosa Filho et al., 2015).

\section{Measures and Procedures}

Body image was evaluated using the nine-silhouettes scale (Stunkard, Sorensen, \& Schulsinger, 1983). The ninesilhouettes scale included illustrations that range from extremely thin (Silhouette 1) to extremely obese (Silhouette 9). Students were asked to select the figure that best represented their current body shape, being the one they "think they look" most like, and the figure that best represented their desired body shape, which would be the one they "wish they looked" most like. The body image perception score was estimated by calculating the difference between real and ideal body images. Positive scores indicated that the subject is dissatisfied with being heavier than ideal or a desire to reduce silhouette. On the other hand, negative scores indicate that the subject is dissatisfied with being lighter than ideal, demonstrating a desire to increase the silhouette. Scores equal to 0 indicated body image satisfaction. This measure has acceptable reliability (2-week intraclass correlation $[\mathrm{ICC}]=0.85$; Barbosa Filho et al., 2015).

Sociodemographic, behavioral, and individual variables are potentially associated factors with body image and were evaluated using a self-reported instrument (Barbosa Filho et al., 2015). The factors used were age-groups, economic class, physical activity level, frequency of condom use, eating habits, alcohol and tobacco use, body mass index (BMI), self-rated health, and healthy body image perception. 
Age was reported and organized into early, aged 11-14 years, and late adolescence, aged 15-17 years (Santrock, 2014). Economic class was evaluated with the questionnaire from the Brazilian Association of Research Companies, which groups subjects into best $(\mathrm{A}+\mathrm{B})$ and worst $(\mathrm{C}+$ $\mathrm{D}+\mathrm{E})$ economic classes based on a score combining ownership of assets, parents' schooling, and number of employees in the household (Brazilian Market Research Association, 2012). Age (ICC $=0.99)$ and economic class $(\mathrm{ICC}=0.93)$ have acceptable reliability (Barbosa Filho et al., 2015).

Physical activity was assessed using a list of 24 types of activities that were validated for Brazilian adolescents (Farias Junior et al., 2012). The weekly volume of physical activity was calculated as the product of the weekly frequency and daily duration of each activity that they performed in a typical week. Thus, the physical activity level, classified as insufficiently active or sufficiently active, was estimated based on physical activity guidelines $(420 \mathrm{~min} /$ week; World Health Organization, 2010). Eating habits were evaluated using 2 items related to daily consumption of fresh fruit and soft drinks in a typical week (yes or no; Silva et al., 2013). Two items on current tobacco and alcohol use in the month preceding the survey, classified as yes or no, and one question on condom use in the year preceding the survey, classified as always use/never had sex and sometimes use/never use, were considered (Silva et al., 2013). These questions had an ICC ranging from 0.71 (physical activity) to 0.99 (tobacco use; Barbosa Filho et al., 2015).

BMI was calculated (body mass divided by height squared, $\mathrm{kg} / \mathrm{m}^{2}$ ) and classified according to international cutoff points (Onis, Onyango, Borghi, Nishida, \& Siekmann, 2007). Self-rated health was measured using the question, "Overall, how would you rate your health?," and the answer scale was dichotomized as very good/good or regular/bad.

Finally, the nine-silhouettes scale was used to identify the students' perception of a healthy body image. The difference between real and healthy body image was calculated in order to identify whether students perceived their body image as healthy or unhealthy (yes or no). These measures had an ICC higher than .80 (Barbosa Filho et al., 2015).

The dichotomization of the outcome is due to the focus of the study on the prevalence of adolescents' perception of body image and possible associated factors. This is the reason why dichotomization was necessary, since it allows identifying the subgroups of adolescents more prone to this outcome (Barbosa Filho et al., 2015).

Data collection was conducted in July 2014. The questionnaire was administered by evaluators to students in the classroom. Data were computed by scanning using the SPHYNX ® software (version 5.1) (Sphynx Software Solutions Inc., Washington, DC), with correction for error and/or inconsistencies.

\section{Data Analysis}

Absolute and relative frequencies were used for description of categorical variables. The $\chi^{2}$ test for linear trends was used in order to compare variables between boys and girls. Multinomial logistic regression analysis was used to estimate odds ratio $(O R)$ and a confidence interval $(\mathrm{CI})$ of 95\% CI in order to identify factors associated with body image in boys and girls separately. The dependent variable was body image perception $(0=$ satisfied; $1=$ dissatisfied, desire to reduce silhouette; and $2=$ dissatisfied, desire to increase silhouette). The inclusion of independent variables in the regression model was performed using a hierarchical approach (Victora, Huttly, Fuchs, \& Olinto, 1997), considering three levels: sociodemographic, behavioral, and individual variables. We initially used the adjustment of the first-level variables. Analyses of subsequent levels controlled for the variables from the same level and those from the previous level. The final significance level was 5\% ( $p$ value $<.05$ for two-tailed tests). All analyses were conducted using the SPSS 23.0 statistical software (SPSS IBM Inc., Chicago, IL).

\section{Results}

The final sample included 609 boys and 573 girls. Higher proportions of students who had the best economic condition ( $29.4 \%$ vs. $21.9 \%)$, who were sufficiently active ( $56.3 \%$ vs. $26.7 \%)$, who reported condom use sometimes/never $(20.2 \%$ vs. $8.2 \%)$, and who reported current tobacco use $(8.0 \%$ vs. $5.1 \%)$ were observed in boys compared to girls $(p<.05)$. Inversely, a higher proportion of overweight/obesity $(27.1 \%$ vs. $23.7 \%)$ and negative health perception $(32.1 \%$ vs. $23.8 \%)$ were observed in girls $(p<.05)$. All other variables were similar between boys and girls $(p>.05$, Table 1$)$.

Most boys (76.9\%) and girls (77.5\%) were dissatisfied with their body image mainly because they desired to increase their silhouette (45.1\% and $39.6 \%$ in boys and girls, respectively). There was no statistically significant difference between boys and girls for body image perception ( $p=$ .285 , Figure 1).

Age-groups and economic class were not associated with body image dissatisfaction among boys $(p>.05)$. Boys who reported daily fruit consumption had a $43 \%$ lower chance of desiring to increase their silhouette in comparison to peers who did not eat fruit daily $(p=.035)$. All other behavioral variables were not associated with body image in boys.

BMI status was an individual variable associated with body image dissatisfaction in boys $(p<.001)$. Overweight $(O R=3.96)$ and obese $(O R=36.5)$ boys had a higher $O R$ of desiring to reduce their silhouette when compared to normal weight boys. Also, a lower $O R$ of desiring to increase their silhouette was observed in overweight $(O R=0.14)$ and obese $(O R=0.12)$ boys in comparison to normal weight boys $(p<.001)$. Boys who perceived their body as an 
Table I. Description of the Sample of Boys and Girls.

\begin{tabular}{|c|c|c|c|c|c|}
\hline \multirow{2}{*}{ Variables } & \multicolumn{2}{|c|}{ Boys $(n=609)$} & \multicolumn{2}{|c|}{ Girls $(n=573)$} & \multirow{2}{*}{$p$ Value } \\
\hline & $n$ & Percentage & $n$ & Percentage & \\
\hline \multicolumn{6}{|l|}{ School grade } \\
\hline Seventh & 252 & 41.4 & 241 & 42.1 & .815 \\
\hline Eighth & 224 & 36.8 & 201 & 35.1 & \\
\hline Ninth & 133 & 21.8 & 131 & 22.9 & \\
\hline \multicolumn{6}{|l|}{ Age-groups (years) } \\
\hline $11-14$ & 456 & 75.1 & 465 & 81.4 & .009 \\
\hline $15-18$ & $|5|$ & 24.9 & 106 & 18.6 & \\
\hline \multicolumn{6}{|l|}{ Socioeconomic status } \\
\hline$C+D+E$ (worse condition) & 425 & 70.6 & 447 & 78.1 & .003 \\
\hline$A+B$ (best condition) & 177 & 29.4 & 125 & 21.9 & \\
\hline \multicolumn{6}{|l|}{ Physical activity level } \\
\hline Insufficiently active & 266 & 43.7 & 420 & 73.3 & $<.001$ \\
\hline Sufficiently active & 343 & 56.3 & 153 & 26.7 & \\
\hline \multicolumn{6}{|l|}{ Condom use } \\
\hline Always used/Never had sex & 486 & 79.8 & 526 & 91.8 & $<.001$ \\
\hline Sometimes used/Never used & 123 & 20.2 & 47 & 8.2 & \\
\hline \multicolumn{6}{|l|}{ Daily consumption of fresh fruit } \\
\hline No & 486 & 79.8 & 474 & 82.7 & .199 \\
\hline Yes & 123 & 20.2 & 99 & 17.3 & \\
\hline \multicolumn{6}{|l|}{ Daily consumption of soft drinks } \\
\hline No & 445 & 73.1 & $4 \mid 4$ & 72.3 & .752 \\
\hline Yes & 164 & 26.9 & 159 & 27.7 & \\
\hline \multicolumn{6}{|l|}{ Current alcohol use } \\
\hline No & 465 & 76.4 & 445 & 77.7 & .594 \\
\hline Yes & 144 & 23.6 & 128 & 22.3 & \\
\hline \multicolumn{6}{|l|}{ Current tobacco use } \\
\hline No & 560 & 92.0 & 544 & 94.9 & .039 \\
\hline Yes & 49 & 8.0 & 29 & 5.1 & \\
\hline \multicolumn{6}{|l|}{ BMI status } \\
\hline Normal weight & 453 & 76.3 & 405 & 73.0 & .015 \\
\hline Overweight & 66 & II.I & 93 & 16.8 & \\
\hline Obesity & 75 & 12.6 & 57 & 10.3 & \\
\hline \multicolumn{6}{|l|}{ Self-rated health } \\
\hline Very good/good & 464 & 76.2 & 389 & 67.9 & .001 \\
\hline Regular/bad & 145 & 23.8 & 184 & 32.1 & \\
\hline \multicolumn{6}{|l|}{ Healthy body image perception } \\
\hline Had a healthy body & 166 & 27.3 & 144 & 25.1 & .406 \\
\hline Did not have a healthy body & 443 & 72.7 & 429 & 74.9 & \\
\hline
\end{tabular}

${ }^{\text {a }} p$ value estimated using the $\chi^{2}$ test.

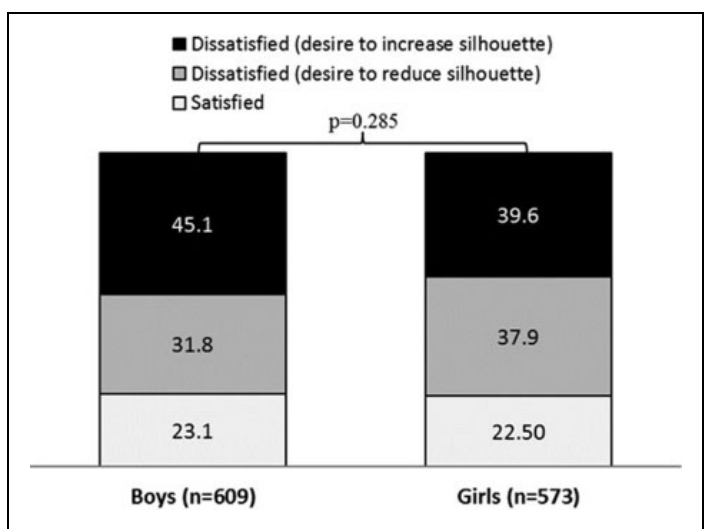

Figure I. Perception of body image among Brazilian boys and girls. unhealthy body had higher $O R$ of desiring to reduce $(O R=$ $4.80, p<.001)$ or increase $(O R=9.89, p<0.001)$ their silhouette in comparison to peers who perceived having a healthy body (Table 2).

In girls, sociodemographic and behavioral variables were not significantly associated with body image dissatisfaction $(p>.05)$. However, BMI status and healthy body image perception were significantly associated with body image dissatisfaction $(p<.001)$. Overweight $(O R=5.24)$ and obese $(O R=50.85)$ girls had a higher $O R$ of desiring to reduce their silhouette in comparison to normal weight girls. Also, students from these groups had a lower $O R$ of desiring to increase their silhouette compared to normal weight girls. Girls who perceived their body as an unhealthy body had a 
Table 2. Factors Associated With Body Image Dissatisfaction in Boys.

\begin{tabular}{|c|c|c|c|c|c|c|}
\hline Variables & \multicolumn{3}{|c|}{ Dissatisfied (Desire to Reduce Silhouette) } & \multicolumn{3}{|c|}{ Dissatisfied (Desire to Increase Silhouette) } \\
\hline Age-groups (years) & & & .862 & & & .150 \\
\hline $11-14$ & 32.8 & Reference & & 43.2 & Reference & \\
\hline $15-18$ & 29.1 & $\mathrm{I} .05[0.6 \mathrm{I}, \mathrm{I} .79]$ & & 50.3 & $\mathrm{I} .43(0.88 ; 2.33]$ & \\
\hline$C+D+E$ (worse condition) & 31.2 & $0.89[0.55,1.44]$ & & 45.6 & $0.98[0.62,1.55]$ & \\
\hline \multicolumn{7}{|l|}{ Block 2: Behavioral variables } \\
\hline Physical activity level & & & .862 & & & .461 \\
\hline Insufficiently active (<420 min/week) & 32.1 & Reference & & 46.4 & Reference & \\
\hline Sufficiently active ( $\geq 420 \mathrm{~min} /$ week) & 31.6 & $\mathrm{I} .05[0.6 \mathrm{I}, \mathrm{I} .79]$ & & 44.2 & $0.85[0.55,1.3 \mathrm{I}]$ & \\
\hline Condom use & & & .638 & & & .716 \\
\hline Yes & 36.6 & $0.83[0.52,1.32]$ & & 35.8 & $0.57[0.33,0.96]$ & \\
\hline Daily consumption of soft drinks & & & .436 & & & .450 \\
\hline No & 30.2 & Reference & & 45.6 & Reference & \\
\hline Yes & 36.0 & $0.79[0.44,1.42]$ & & 43.9 & $1.21[0.74,1.99]$ & \\
\hline Current alcohol use & & & .663 & & & .971 \\
\hline No & 29.6 & Reference & & 46.0 & Reference & \\
\hline Yes & 38.9 & $0.88[0.52, \mathrm{I} .5 \mathrm{I}]$ & & 42.0 & $0.99[0.56,1.75]$ & \\
\hline Current tobacco use & & & .318 & & & .517 \\
\hline No & 30.6 & Reference & & 45.5 & Reference & \\
\hline Yes & 44.9 & I.3I $[0.77,2.20]$ & & 40.8 & I. $37[0.53,3.57]$ & \\
\hline \multicolumn{7}{|l|}{ Block 3: Individual variables } \\
\hline BMI status & & & $<.001$ & & & $<.001$ \\
\hline Had a healthy body & 20.5 & Reference & & 27.1 & Reference & \\
\hline Did not have a healthy body & 36.1 & $4.80[2.68,8.58]$ & & 51.9 & $9.89[5.94,16.44]$ & \\
\hline
\end{tabular}

Note. $n=609$.

${ }^{a}$ Odds ratio $(O R)$, confidence interval $(\mathrm{Cl})$ of $95 \%$, and $p$ value were estimated using multinomial logistic regression. The boldface values above show the significance $p<0.05$.

higher $O R$ of desiring to reduce their silhouette $(O R=4.56)$ or to increase $(O R=9.83)$ their silhouette in comparison to peers who perceived they had a healthy body (Table 3 ).

\section{Discussion}

The present study found that approximately 8 of the 10 students were dissatisfied with their body image, with similar estimates between boys and girls. A surprising result was that most students were dissatisfied with their body image because they desired to increase their silhouette $(45.1 \%$ and $39.6 \%$ in boys and girls, respectively). This dissatisfaction with body image is alarming due to adolescents' vulnerability for eating disorders such as anorexia and bulimia and can be explained by the desirable silhouette promoted by the media, peer standards, and models (Gonçalves, Moreira, Trindade, \& Fiates, 2013). Studies have revealed the presence of eating disorders in adolescents because of the influence from family, for example, strict dietary rules, exposure to media and nutritional problems, stunted growth and weight gain, and the induction of vomit or intake of laxatives as procedures to achieve the ideal body image (Fidelix, Minatto, Ribeiro, Santos, \& Petroski, 2013; IBGE, 2013; Iepsen \& Silva, 2014).

Elevated BMI was associated with body image dissatisfaction in both genders, which was confirmed in previous 
Table 3. Factors Associated With Body Image Dissatisfaction in Girls.

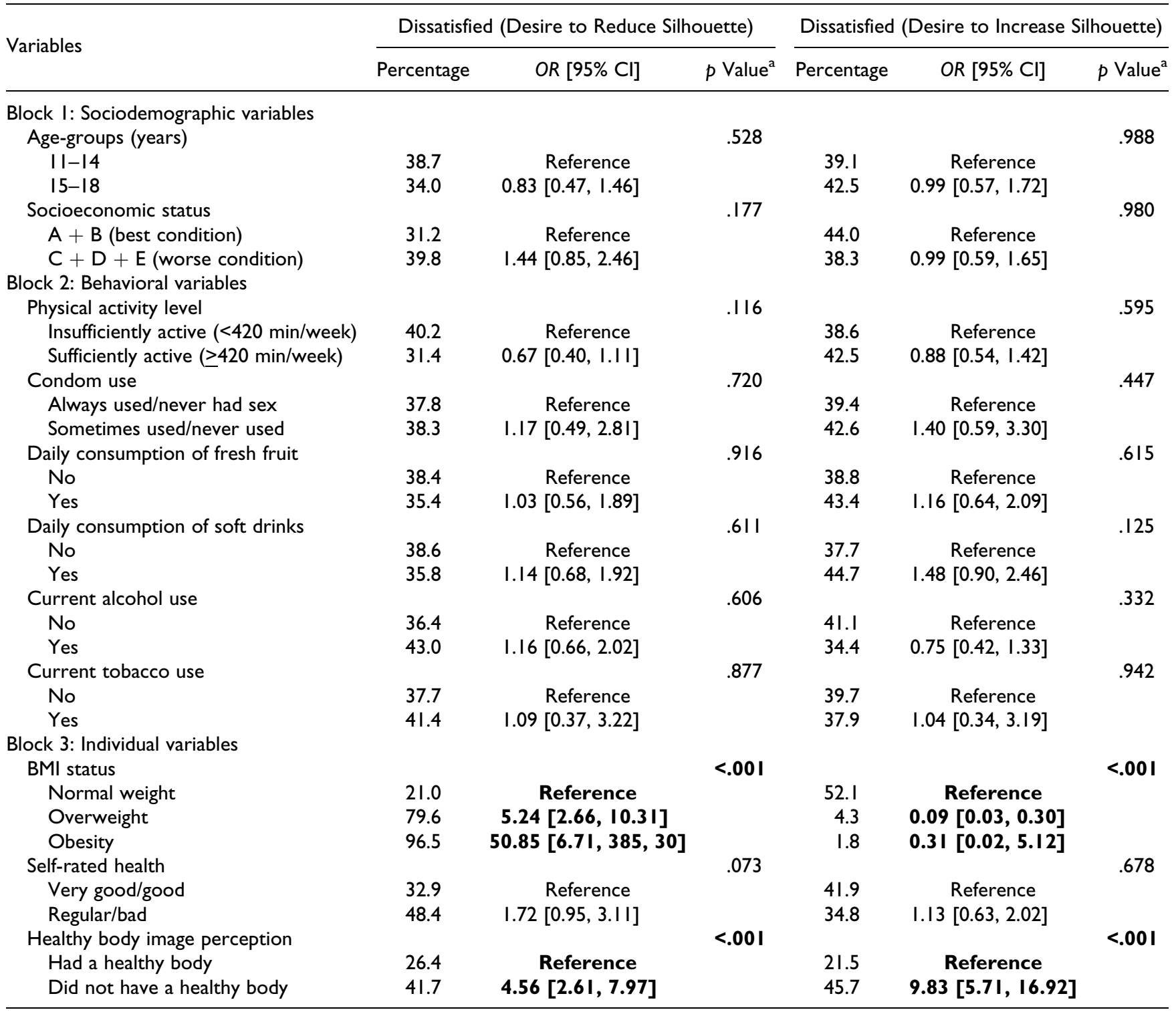

Note. $n=573$.

${ }^{a}$ Odds ratio $(O R)$, confidence interval $(\mathrm{Cl})$ of $95 \%$, and $p$ value were estimated using multinomial logistic regression. The boldface values above show the significance $p<0.05$.

studies (Finato et al., 2013; Glaner, Pelegrini, Cordoba, \& Pozzobon, 2013; Pedroni et al., 2013). This dissatisfaction may be related to a constant "thin and beautiful" body reference used in the media, which can affect how adolescents view themselves, and thus suffer from the influence of the society of women must be thin, men must be strong (Del Ciampo \& Del Ciampo, 2010; Mäkinen et al., 2015). Media and social dissemination of obesity-related health problems is important in health promotion and disease prevention in public policies, but when not satisfactorily achieved by the individual, can increase body image dissatisfaction.

The present study found a strong association between the perception of a healthy body and body image among boys and girls. As mentioned earlier, the cognitive process of building a concept of "ideal" body image and its discrepancies with the "real" body image can be influenced by social relationships and impositions. The adolescent's concept of a "healthy" body image is not different (Hong et al., 2015; Hyun et al., 2014; Pereira, Prado, Filipini, Felipe, \& Terra, 2012; Silva, Taquette, \& Coutinho, 2014), and dissatisfaction with healthy body image evaluation seems to be closely related to body image dissatisfaction. This evidence is important because health education actions can promote the understanding that patterns of a "healthy body" are not corresponding to a holistic definition of health including social and mental 
aspects; combating body image dissatisfaction in adolescence seems to be important.

This study showed no association between body image and sociodemographic variables, which corroborates previous studies (Caccavale, Farhat, \& Iannotti, 2012; Fidelix et al., 2011). Similarly, most behavioral variables were not associated with body image perception among boys and girls in the present study, which is different from other studies that observed a negative influence of risk behaviors, for example, physical inactivity, tobacco use, and alcohol use, on body image perception in adolescents (Caccavale et al., 2012; Lamis et al., 2010; Lundberg et al., 2011). These differences may be due to the peculiarity of the sample in terms of behavior, for example, most adolescents did not use tobacco or initiate sexual behaviors, and socioeconomic aspects, as most adolescents were from a low economic class and lived in low HDI areas.

Daily consumption of fruit was the only behavioral factor significantly and positively associated with body image perception in this study, but only among boys, that is, daily fruit consumption had a $43 \%$ lower chance of desiring to increase their silhouette in comparison to peers who did not eat fruit daily. This result shows that healthy eating habits can be important to both physical and psychological health including body image satisfaction (Barbosa, Matos, \& Costa, 2011; Pérez-Gil, Paz, \& Romero, 2011).

\section{Strengths and Limitations}

To our knowledge, this was one of the first studies to focus on evaluating body image dissatisfaction and associated factors in a sample of adolescents from low HDI areas. Still, the composition of potentially associated factors including sociodemographic, behavioral, and individual variables was important to show how different variables are associated with body image perception; this can guide intervention strategies focused on body image satisfaction among young people.

One limitation was the self-report measurement of some variables, especially physical activity and eating habits. Although reliable instruments were used (Barbosa Filho et al., 2015), there are possible recall limitations for these items. Also, although the measure of body image using the nine-silhouettes scale is acceptable (Fidelix et al., 2013; Stunkard et al., 1983), there was no breakdown of dissatisfaction with body image for body parts, which could indicate different results, for example, the relationship between physical activity and body image is significant for specific body parts.

In addition, due to its cross-sectional nature, it was possible to examine associations between risk factors, that is, sociodemographic, behavioral, and individual variables, and body image perception. However, it's not possible to determine their causal relationships. Finally, another limitation of this study is that it was performed locally.

\section{Implications for Nursing Research and Practice}

Education and health care focused on body image must pay special attention to young people from vulnerable areas with high BMI and focus on strategies that enable improving the perception of a healthy body and a healthy eating, especially boys.

These results suggest attention to the perception of healthy body image evaluation and eating behaviors during educational activities in the family, as well as consultations or home visits, and school contexts with health education lessons.

The results of this study can help health professionals, sectors, and institutions to identify which individual and social aspects can be the focus of effective strategies for health promotion and education among adolescents.

\section{Authors' Note}

Thábyta Silva de Araujo contributed to conception, design, acquisition of data, analysis, and interpretation of data; drafted the article; and gave final approval of the version to be published. Valter Cordeiro Barbosa Filho contributed to analysis and interpretation of data, critically revised the manuscript for important intellectual content, and gave final approval of the version to be published. Fabiane do Amaral Gubert gave final approval of the version to be published. Paulo César de Almeida critically revised the manuscript for important intellectual content and gave final approval of the version to be published. Mariana Cavalcante Martins critically revised the manuscript for important intellectual content and gave final approval of the version to be published. Queliane Gomes da Silva Carvalho critically revised the manuscript for important intellectual content and gave final approval of the version to be published. Ana Cristina Pereira de Jesus Costa critically revised the manuscript for important intellectual content and gave final approval of the version to be published. Neiva Francenely Cunha Vieira contributed to analysis and interpretation of data, critically revised the manuscript for important intellectual content, and gave final approval of the version to be published.

\section{Declaration of Conflicting Interests}

The author(s) declared no potential conflicts of interest with respect to the research, authorship, and/or publication of this article.

\section{Funding}

The author(s) received no financial support for the research, authorship, and/or publication of this article.

\section{References}

Barbosa, M. R., Matos, P. M., \& Costa, M. E. (2011). A glance into the body: Yesterday's and today's body. Psicologia \& Sociedade, 23, 24-34.

Barbosa Filho, V. C., Lopes, A. S., Lima, A. B., Souza, E. A., Gubert, F. A., Silva, K. S., ... Mota, J. (2015). Rationale and methods of a cluster-randomized controlled trial to promote active and healthy lifestyles among Brazilian students: The "Fortaleça sua Saúde" program. BMC Public Health, 15, 1-15. 
Brazilian Market Research Association [Associação Brasileira de Empresas de Pesquisas] (2012). Brazilian economic classification criteria [in Portuguese]. São Paulo, SP. Retrieved from www.abep.org

Caccavale, L. J., Farhat, T., \& Iannotti, R. J. (2012). Social engagement in adolescence moderates the association between weight status and body image. Body Image, 9, 221-226.

Carvalho, E. S. S., Paiva, M. S., \& Aparício, E. C. (2013). Awkward bodies, but not forgotten: Representations of women and men about their wounded bodies. Revista Brasileira De Enfermagem, 66, 90-96.

Cortês, M. G., Meireles, A. L., Friche, A. A. L., Caiaffa, W. T., \& Xavier, C. C. (2013). Silhouette scales and body satisfaction in adolescents: A systematic literature review. Cadernos de Saúde Pública, 29, 427-444.

Del Ciampo, L. A., \& Del Ciampo, I. R. L. (2010). Adolescence and body image. Adolescência e Saúde, 7, 55-59.

Farhat, T., Iannotti, R. J., \& Caccavale, L. J. (2014). Adolescent overweight, obesity and chronic disease-related health practices: Mediation by body image. Obesity Facts, 7, 1-14.

Farias Junior, J. C., Lopes, A. S., Mots, J., Santos, M. P., Ribeiro, J. C., \& Hallal, P. C. (2012). Validity and reproducibility of a physical activity questionnaire for adolescents: Adapting the self-administered physical activity checklist. Revista Brasileira de Epidemiologia, 15, 198-210.

Fidelix, Y. L., Minatto, G., Ribeiro, R. R., Santos, K. D., \& Petroski, E. L. (2013). Sociodemographic data, nutritional status and sexual maturation of male students: Exposure to dissatisfaction with body image. Revista da Educação Fisical UEM, 24, 83-92.

Fidelix, Y. L., Silva, D. A. C., Pelegrini, A., Silva, A. F., \& Petroski, E. L. (2011). Body image dissatisfaction among adolescents from a small town: Association with gender, age, and area of residence. Revista Brasileira de Cineantropometria e Desempenho Humano, 13, 202-207.

Finato, S., Rech, R. R., Migon, P., Gavineski, I. C., Toni, V., \& Halpern, R. (2013). Body image insatisfaction in students from the sixth grade of public schools in Caxias do Sul, Southern Brazil. Revista Paulista de Pediatria, 31, 65-70.

Glaner, M. F., Pelegrini, A., Cordoba, C. O., \& Pozzobon, M. E. (2013). Association between body image dissatisfaction and anthropometric indicators in adolescents. Revista Brasileira de Educação Física e Esporte, 27, 129-136.

Gonçalves, J. A., Moreira, E. A. M., Trindade, E. B. S. M., \& Fiates, G. M. R. (2013). Eating disorders in childhood and adolescence. Revista Paulista de Pediatria, 31, 96-103.

Hernando, Á, Nunes, C., Torres, C. C., Lemos, I., \& Valadas, S. (2013). A comparative study on the health and well-being of adolescent immigrants in Spain and Portugal. Saúde e Sociedade São Paulo, 22, 342-350.

Hong, S. C., Jung, Y. E., Kim, M. D., Lee, C. I., Hyun, M. Y., Bahk, W. M., ... Lee, K. H. (2015). Prevalence of distorted body image in young Koreans and its association with age, sex, body weight status, and disordered eating behaviors. Neuropsychiatric Disease and Treatment, 11, 1043-1049.
Hyun, M. Y., Jung, Y. E., Kim, M. D., Kwak, Y. S., Hong, S. C., Bahk, W. M., ... Yoo, B. (2014). Factors associated with body image distortion in Korean adolescents. Neuropsychiatric Disease and Treatment, 10, 797-802.

Iepsen, A. M., \& Silva, M. C. (2014). Body image dissatisfaction prevalence and associated factors among adolescents at rural high schools in the southern region of Rio Grande do Sul State, Brazil, 2012. Epidemiologia e Serviços de Saúde, 23, 317-325.

Instituto Brasileiro de Geografia e Estatística. (2010). Population 2010. Rio de Janeiro, Brazil: Author. Retrieved from http:// cidades.ibge.gov.br/xtras/perfil.php?codmun $=230440 \&$. In Portuguese.

Instituto Brasileiro de Geografia e Estatística. (2013). Pesquisa Nacional de Saúde do Escolar 2012. Rio de Janeiro, Brazil: Author. Retrieved from http://censo2010.ibge.gov.br/. In Portuguese.

Lamis, D. A., Malone, P. S., Langhinrichsen-Rohling, J., \& Ellis, T. E. (2010). Body investment, depression, and alcohol use as risk factors for suicide proneness in college students. Crisis, 31, 118-127.

Langoni, P. O. O., Aerts, D. R. G. C., Alves, G. G., \& Câmara, S. G. (2012). Body image dissatisfaction and associated factors in scholastic adolescents. Revista da SPRGS, 11, 23-30.

Laus, M. F., Kakeshita, I. S., Costa, T. M. B., Ferreira, M. E. C., Fortes, L. S., \& Almeida, S. S. (2014). Body image in Brazil: Recent advances in the state of knowledge and methodological issues. Revista de Saúde Pública, 48, 331-346.

Lee, J., \& Lee, Y. (2016). The association of body image distortion with weight control behaviors, diet behaviors, physical activity, sadness, and suicidal ideation among Korean high school students: A cross-sectional study. BMC Public Health, 16, 1-10.

Lundberg, P., Rukundo, G., Ashaba, S., Thorson, A., Allebeck, P., Östergren, P., \& Cantor-Graae, E. (2011). Poor mental health and sexual risk behaviors in Uganda: A cross-sectional population-based study. BMC Public Health, 11, 1-10.

Mäkinen, M., Marttunen, M., Komulainen, E., Terevnikov, V., Puukko-Viertomies, L. R., Aalberg, V., \& Lindberg, N. (2015). Development of self-image and its components during a one-year follow-up in non-referred adolescents with excess and normal weight. Child and Adolescent Psychiatry and Mental Health, 9, 1-9.

Malik, K. (2014). Human Development Report 2014. Sustaining human progress: reducing vulnerabilities and building resilience. New York, NY: United Nations Development Programme. Retrieved from http://hdrundporg/sites/default/files/ hdr14-report-en-1_pdf

Onis, M., Onyango, A. W., Borghi, E., Nishida, C., \& Siekmann, J. (2007). Development of a WHO growth reference for schoolaged children and adolescents. Bulletin of the World Health Organization, 85, 660-667.

Paludo, A. C., Pelegrini, A., Grespan, F., Caldeira, A. S., Madureira, A. S., \& Serassuelo Junior, H. (2011). Dissatisfaction with body image in adolescents: Prevalence and association with nutritional status. ConScientiae Saúde, 10, 143-149. 
Pedroni, J. L., Rech, R. R., Halpern, R., Marin, S., Roth, L. R., Sirtoli, M., \& Cavalli, A. (2013). Prevalence of abdominal obesity and excess fat in students of a city in the mountains of southern Brazil. Revista Ciência \& Saúde Coletiva, 18, 1417-1425.

Pereira, B. B. S., Prado, B. O., Filipini, C. B., Felipe, A. O. B., \& Terra, F. S. (2012). Evaluation of nurses' knowledge against growth and development of adolescents. Adolescencia e Saúde, 9, 19-26.

Pérez-Gil, S. E., Paz, C., \& Romero, G. (2011). Body, image and nutritious knowledge in Oaxaca, Mexico, infants: A first approximation. Revista Latinoamericana de Ciencias Sociales, Ninez y Juventud, 9, 847-868.

Petroski, E. L., Pelegrini, A., \& Glaner, M. F. (2012). Reasons and prevalence of body image dissatisfaction in adolescents. Ciencia \& Saúde Coletiva, 17, 1071-1077.

Reina, S. A., Shomaker, L. B., Mooreville, M., Courville, A. B., Brady, S. B., Olsen, C., . . Y Yanovski, J. A. (2013). Sociocultural pressures and adolescent eating in the absence of hunger. Body Image, 10, 182-190.

Ribeiro, P. C. P., \& Oliveira, P. B. R. (2011). Body image: Beauty or disease? Adolescência e Saúde, 8, 63-69.

Santrock, J. W. (2014). Adolescence (14th ed.). Porto Alegre, RS: AMGH.

Silva, K. S., Lopes, A. S., Hoefelmann, L. P., Cabral, L. G. A., De Bem, M. F. L., Barros, M. V. G., \& Nahas, M. V. (2013). Health risk behaviors project (COMPAC) in youth of the Santa Catarina State, Brazil: Ethics and methodological aspects. Revista Brasileira de Cineantropometria e Desempenho Human, 15, $1-15$.

Silva, M. L. A., Taquette, S. R., \& Coutinho, E. S. F. (2014). Senses of body image in adolescents in elementary school. Revista de Saúde Pública, 48, 438-444.

Stunkard, A. J., Sorensen, T., \& Schulsinger, F. (1983). Use of the Danish adoption register for the study of obesity and thinness. Res Publ Assoc Res Nerv Ment Dis, 60, 115-120.
United Nations Development Programme. (2016). Human development report 2016-Human development for everyone. New York, NY: Author. Retrieved from http://hdr.undp.org/sites/ default/files/2016_human_development_report.pdf

Victora, C. G., Huttly, S. R., Fuchs, S. C., \& Olinto, M. T. A. (1997). The role of conceptual frameworks in epidemiological analysis: A hierarchical approach. International Journal of Epidemiology, 26, 224-227.

World Health Organization. (2010). Global recommendations on physical activity for health. Geneva, Switzerland: Author. Retrieved from http:/www.who.int/dietphysicalactivity/publi cations/9789241599979/en/

\section{Author Biographies}

Thábyta Silva de Araujo is a PhD student at Federal University of Ceará at Brazil.

Valter Cordeiro Barbosa Filho, $\mathrm{PhD}$, is assistant professor at Federal University of Santa Catarina, Brazil

Fabiane do Amaral Gubert, PhD, is professor at Federal University of Ceará at Brazil.

Paulo César de Almeida, $\mathrm{PhD}$, is professor at State University of Ceará, Brazil

Mariana Cavalcante Martins, $\mathrm{PhD}$, is professor at Federal University of Ceará at Brazil.

Queliane Gomes da Silva Carvalho is a PhD student at Federal University of Ceará at Brazil.

Ana Cristina Pereira de Jesus Costa, $\mathrm{PhD}$, is professor at Federal University of Maranhão, Brazil

Neiva Francenely Cunha Vieira, $\mathrm{PhD}$, is professor at Federal University of Ceará at Brazil. 